
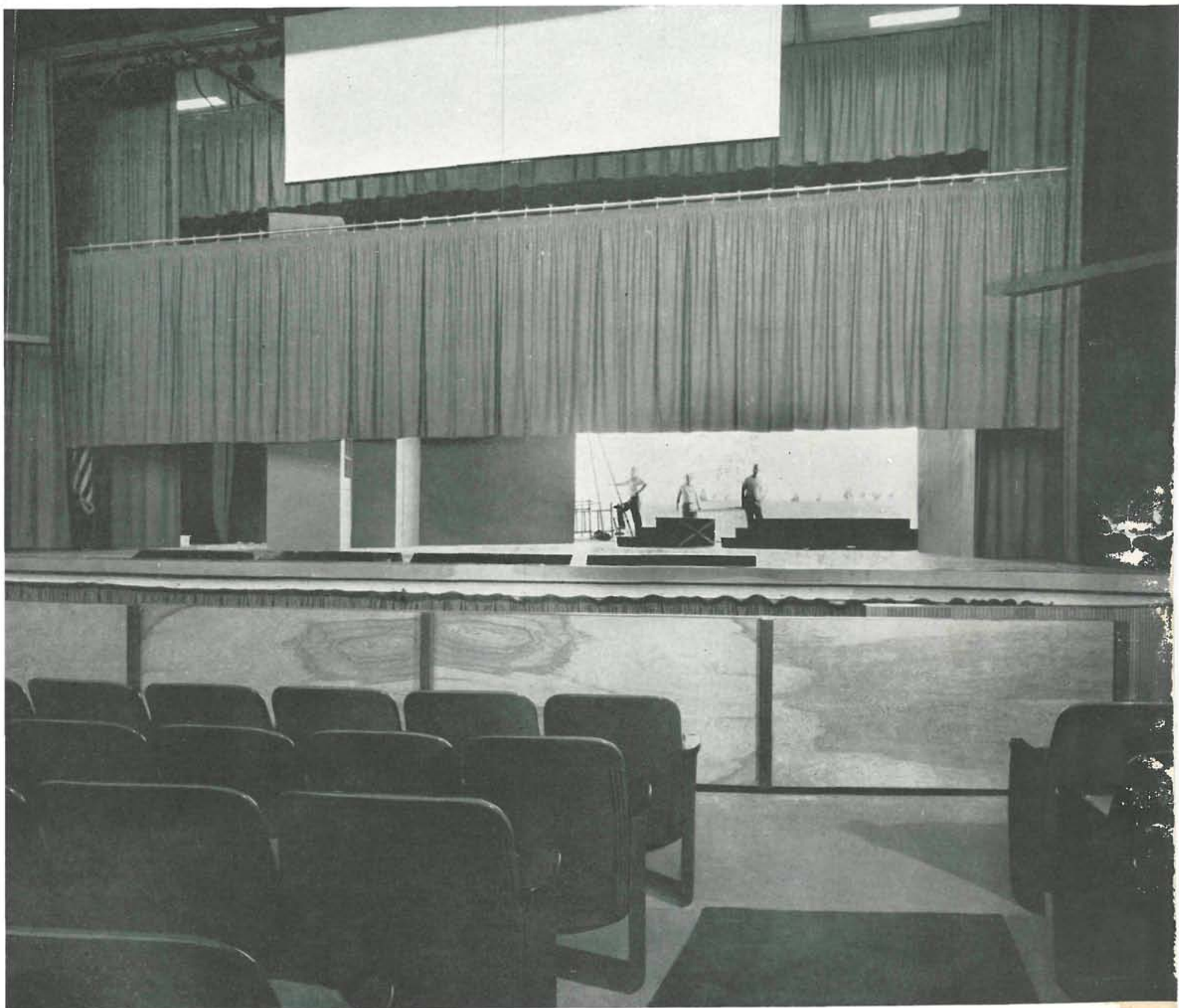

$146 \cdot 57$

\title{
investigaciones sobre el teatro su fisiología
}




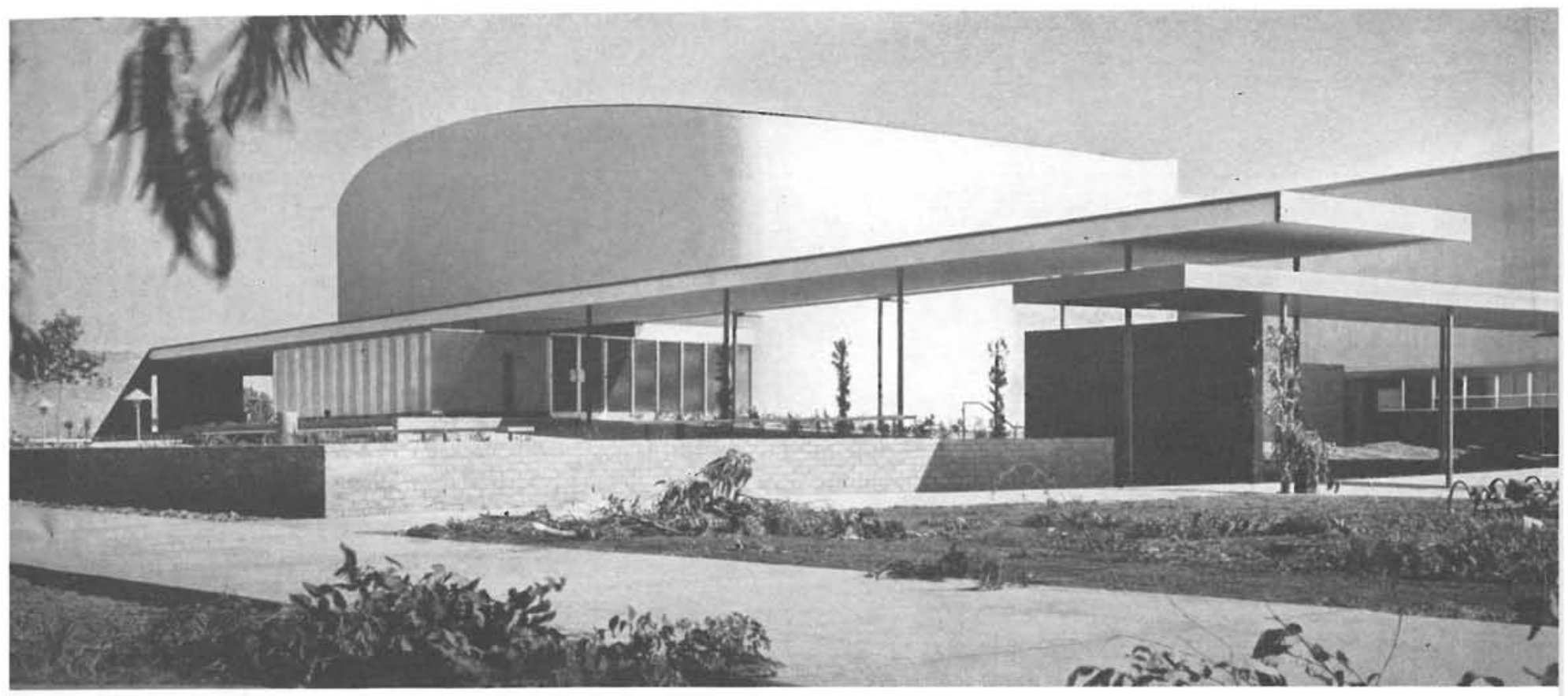

Orange Coast College: Exterior y escenario.

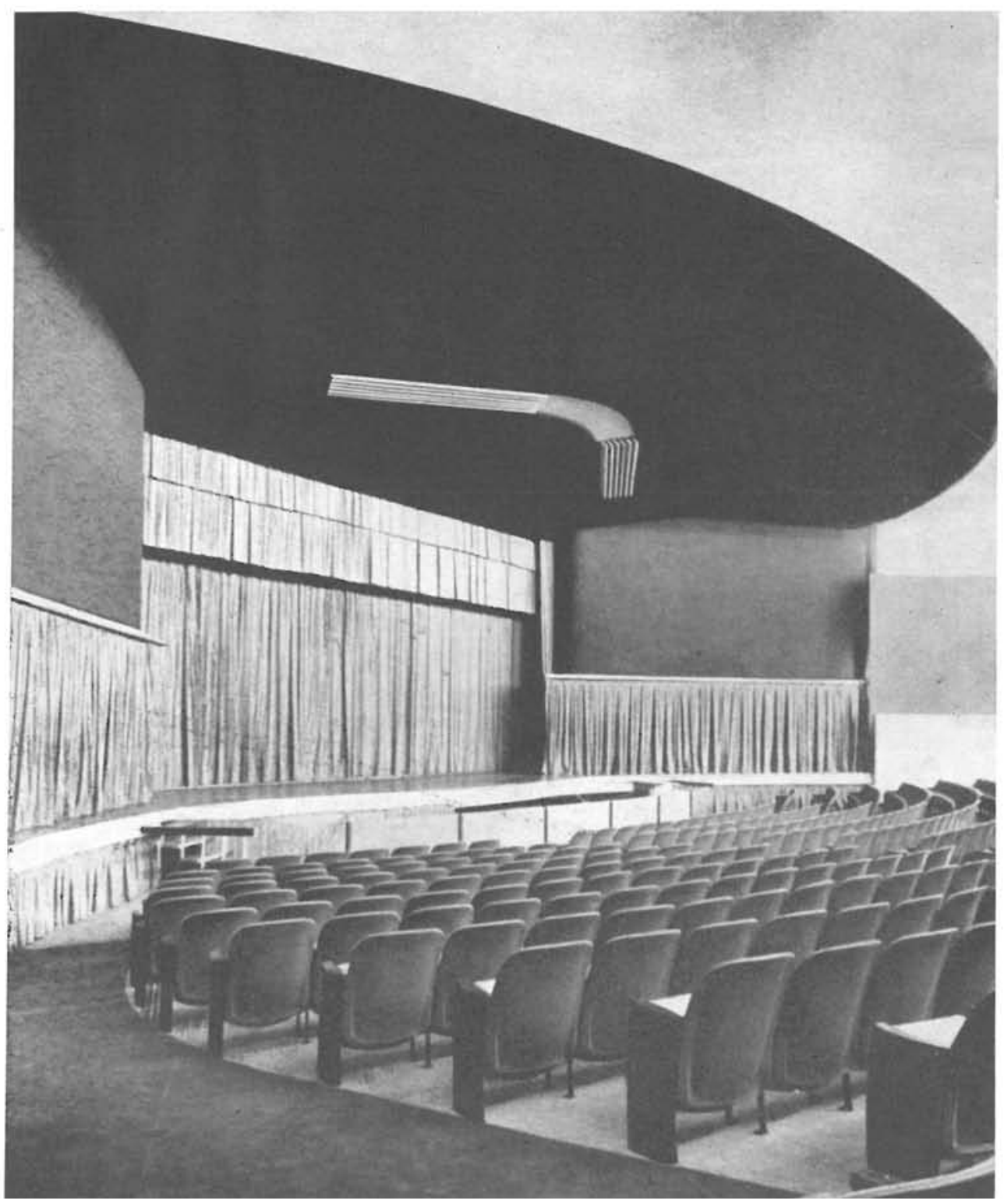



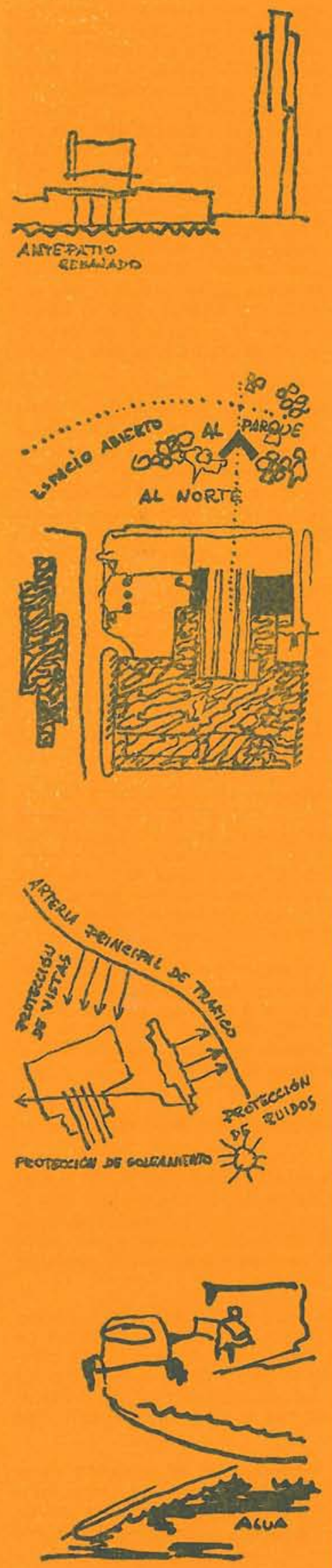

Neutra ha sido invitado, como "El Americano", a tomar parte en un gran Concurso para la construcción del más famoso teatro municipal de Alemania.

Su proyecto obtuvo el primer premio.
Próximo al más alto y más notable ediflcio de oflcinas de Europa-terminado recientemente para la flrma comercial "Rheinrohr", constructora de fabulosos oleoductos en Arabia y Venezuela-, se ha emplazado uno de los más importantes teatros del viejo Continente, de un Continente de gran cultura y solera teatral.

El teatro da a un antiguo parque del siglo xvIII, cuya proximidad el arquitecto decidió tener en cuenta, creando no un basamento elevado, sino un patio anterior rehundido. Se trata del patio de las Tres Musas, que se levantan allí en un grupo abstractamente armónico. La fuente de Hippocrene (fuente del monte Helicón, consagrada a Apolo y a las Musas) y un gran estanque reflectante prestan mayor riqueza. Sobre un puente pasea el público hacia una terraza elevada, para fumar allí en los entreactos y observar la luna en lo alto y el parque abajo.

En Europa es un caso insólito que un monumento municipal, tal como un teatro, quede dominado por una torre de cristal, algo así como el edificio de la O.N.U. que éste se levante por encima de la cubierta-terraza del teatro a unos $90 \mathrm{~m}$ de altura.

Pero este teatro está proyectado como la Capilla Miramar, para ser visto desde el cielo: "a vista de ángel", más bien que para una perspectiva "a vista de gusano".

Son extraordinariamente interesantes los efectos de sombras que, sobre los dos edificios del teatro, y sobre el estrado bajo, proyecta su elevado vecino, a lo alto del cual tiene instalada su oflcina uno de los funcionarios más honorables de esta rica ciudad alemana: el "superintendente", el Director de este templo de las Musas. Será visitado por los más importantes huéspedes nacionales, Jefes de Estado y viвjeros de todos los continentes.

El conjunto de edificios y sus terrazas, con espacios ajardinados y estanques reflectantes, serán un centro de frecuentes reuniones de sociedad, y orgullo de esta ciudad que cuenta con pocas industrias, pero que es centro administrativo de mundialmente amplia actividad económica, que busca alcanzar progreso universal.

Se han conservado todos los árboles centenarios; puntos de referencia distantes, para la masa pulsante humana que forma el tráfico de las corrientes metropolitanas. Hay grandes zonas de estacionamiento, especialmente debajo del edificio, accesible por el norte y por el sur. A éstas se llega por un subterráneo, profusamente iluminado, desde el que sube el público, mediante escaleras mecánicas, a los vestíbulos de ambos edificios y a la taquilla. Una taquilla automática exterior sirve para facilitar la venta de entradas durante el día.

Todos los detalles antedichos del proyecto del estrado y acomodo para toda preparación humana y técnica de las representaciones dramáticas han sido alojadas en el interior, con lo que el arquitecto espera conseguir una unidad arquitectónica, que trascienda al tiempo y a la moda. El arquitecto-oriundo de Viena, ciudad única en su entusiasmo por el teatro-, desde su infancia conoció este pujante desarrollo dramático y, además, se dedicó al estudio e investigación del drama y su composición espontánea, intuitiva y artística.

El ámbito interno del teatro, de acuerdo con la palabra griega "Theatron", es un espacio visual, para mirar, pero es también un auditorio donde las cosas han de ser oídas. Más allá de todo esto, y muy por debajo del nivel consciente del espectador, multitud de sensaciones se ofrecen a millones de receptores. Porque ya no vivimos en una época en que los arquitectos proporcionaban a los clientes sólo los "cinco sentidos". El espectador de teatro se encuentra también en un "espacio termal", donde la temperatura empieza a crecer-desde el momento de levantarse el telón-como consecuencia de que centenares de seres lo van caldeando acto tras acto. Asimismo se encuentra en un "espacio de humedad y sequedad" con todas las sensaciones de la piel vigilando su propia superficie de evaporación, a la vez que observa la representación. 

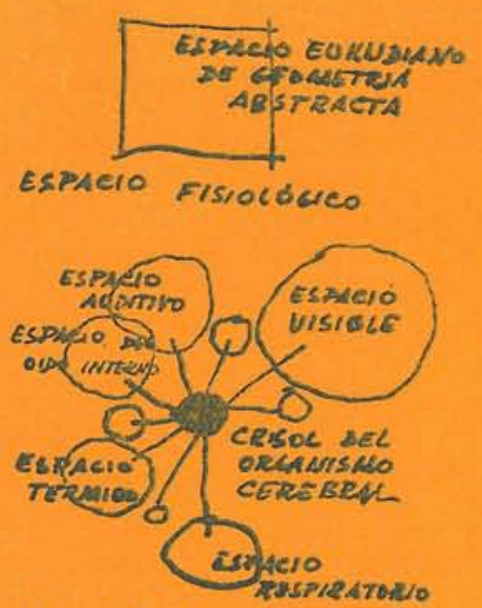

EL ARQUTTECTO AC

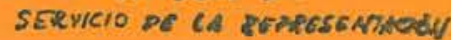

\section{- represeatheion}

DRAMLITICA -
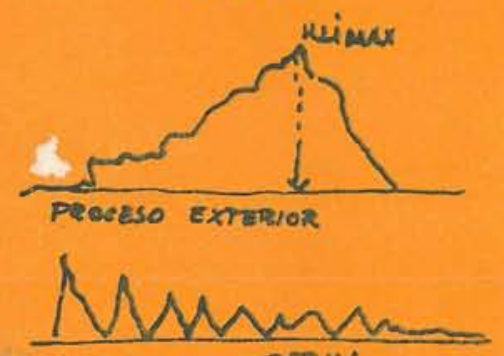

CAPACIDAD INTERUA

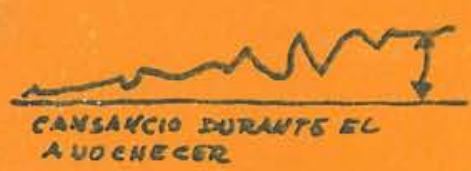

A VOCWECER

Aerivo:

MITR VISUAL
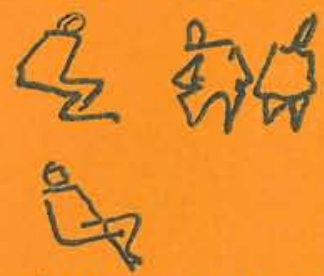

PAsivo: ois meraske
Está rodeado de un espacio de respiración con aire en movimiento, producción de oxígeno y enrarecimiento químico del aire exhalado por él mismo y por sus compañeros. El espectador está en mitad de un espacio en el cual gira e inclina la cabeza con su sentido de aceleración estimulado por el oído interno, y, de este modo, en consonancia con este espacio. Todos sus sentidos internos, musculares e intestinales, los "enteroceptivos" y "propioceptivos" son activados para satisfacerle o disgustarle, mientras él sigue la representación vigilando un esquema iluminativo de color que puede irritar ligeramente su estómago o puede alegrar y deprimir, sucesivamente, su entidad orgánica en su conjunto, tal como ocurre con la nitidez u opacidad de una recepción auditiva, el grado más bajo o más elevado de humedad o la provisión escasa de aire para respirar. Suprimir el ligero olor de las mullidas alfombras en los pasillos y, esperemos asimismo, que se controle el nivel odorífico, creciente allá donde la humanidad se reúne, sea en Nápoles o en Nueva York, para que cumpla su papel subconsciente. Todo el drama "conocido" consiste en que él está esperando a Hamlet en su desesperación y sigue activamente la acción con su cuerpo entero, hasta el último acto: la excitante escena del desafío sobre el verde césped. Pero hay numerosos procesos subconscientes que el arquitecto de teatros puede estimular o disminuir, que puede adormecer la efectividad de los más maravillosos técnicos.

El drama empieza con la experta exposición dramática. Entonces, desde el primero, segundo y tercer actos, la curva sube hacia un climax y, por último, desciende hacia un final que no ha de ser olvidado. Por otra parte, la receptividad fisiológica del auditorio teatral podría presentar otro gráfico diferente por completo, tal que tuviera su punto álgido al principio y fluctuase hacia un mínimo cuando los sentidos han estado expuestos durante largo tiempo. Todavía otro gráfico podría mostrar varios fenómenos de fatiga, nula al principio, pero creciente después, llegando, más tarde, a ser demasiado sustancial para posteriores recepciones.

Todo esto es, como hemos indicado, un paso fisiológico hacia los experimentos dramáticos y un paso también para comprender cuán diferentes y distintas son las llamadas a nuestro ser orgánico, el cual comprende las más complicadas y entrelazadas facetas mientras nosotros creemos que miramos o escuchamos tan sólo. Esto está lejos de todo; pero si nosotros sólo consideramos que lo que vemos con nuestros ojos se transmite a nuestro interior con velocidad supermultiplicada, comparado con lo que oímos, aparece claro, al momento, que todo entronque artificial para recepciones auditivas y visuales no puede lograrse por ningún medio, o no se puede proyectar sabiamente, estando automáticamente combinados.

E1 teatro de Neutra en Dusseldorf no hace concesiones formales sobre lo que es acústicamente deseable. Nosotros no tenemos por qué pensar en consideraciones acústicas cuando nos estamos recreando con formas visuales, del mísmo modo que no nos cuidaríamos de echar una ojeada a la sala de calderas, durante la representación, para estar seguros de que la temperatura y humedad del hall son tomadas en consideración. No obstante, el conjunto de reflejos orgánicos está simultáneamente muy vivo en un ser humano, $y$, de hecho, todo órgano sensorial forma parte de un vigoroso conjunto de actividad. No existe pasividad en ningún aspecto.

Sin embargo, no existe duda alguna de que la perfección visual, por ejemplo, observando un partido de tenis, con el girar de nuestros ojos y el movimiento de nuestra cabeza, parece mucho más activa que la impresión auditiva recibida escuchando a Debussy que es más rebajada. Nuestros dos estereofónicos of́dos son menos éticos y menos rápidos en su movimiento que nuestros dos estereoscópicos ojos. Con un caballo nervioso bien ensefado auditivamente podemos observar las orejas en mayor actividad.

Incidentalmente, una participación más real del observador hace más interna la participación anímica. Esto es psicosomático.

El escenario de Dusseldorf puede ser inmensamente ampliado, de modo que el espectador se encuentre rodeado por la batalla de Filipo, o, por el contrario, puede reducirse grandemente para que dicho espectador se encuentre tranquilamente en la tienda de Bruto escuchando las notas líricas del arpa, tocada en el justo momento en que, con desmayadas luces, el espiritu de César desciende al reducido espacio de su alma anhelante antes de la batalla decisiva.

Pero un teatro no consta solamente de escenas sobre un estrado y cinco actos en plena acción o contenido de reflexión contemplativa. Se compone también de cuatro entreactos. Como es natural el hall del teatro se hace visible solamente cuando se ilumina, después de caer el telón. Ahora las excelencias de los espectadores son visibles en toda su efectividad, y el auditorio se dirige hacia otra parte: todo el mundo empieza a conversar mientras sale a tomar un refresco.

¿Cuál puede ser el oculto papel del entreacto en la totalidad de la representación? ¿Es sólo una interrupción, una distracción? ¿Una interrupción solamente, o también un nexo de enlace, en otro sentido? ¿Tiene alguna significación complementaria, aumentando, intensificando la experiencia de incorporación en el drama? 
Si el público asiste a una representación o a un ritual, en el bosque, mirando al pasar y estando rodeado accidentalmente de árboles, cada espectador tendría una impresión visual distinta y conservaría, por tanto, en la mente un cuadro completamente diferente. Para un grupo determinado puede ocurrir algo semejante, en el "teatro circular", a lo que se promovió en América con el Penthouse Players, en el patio de la Universidad de Seattle. "En un teatro como éste-dice Mr. Neutrapresencié una escena de amor sobre un diván, delante y debajo de mí, del cual había retirado mis propios pies para dejar espacio para esta acción dramática, mientras otro espectador, diametralmente opuesto, ve algo completamente diferente, por supuesto, y probablemente podría identificar a la misma muchacha solamente por el color de su vestido, cuando discutiéramos después de la representación.

El dirigente y director de escena del Dusseldorf tiene una idea diversa respecto a esto. Su salón de espectáculos es un "monoteatro", unificado. El director lo dispone todo para una recepción homogénea ideal, unificada para todos los espectadores. El direccionalismo es una tremenda ayuda y acondicionamiento para hacer la composición de determinda acción dramática contundente y consistente.

Ahora, de la acción desarrollada en el escenario, mientras estamos en la oscuridad, recibimos todas nuestras reverberaciones en intermitencia. Pero tras la intermitencia, nuestra cordura visual vuelve hacia la visión dramática de la escena abierta, para ser captados de nuevo en ese otro mundo. Nosotros vemos el salón iluminado y recibimos de él, nuevamente, la impresionabilidad en el próximo acto a oscuras.

Una anémona de mar, estimulada durante diez segundos, reacciona ante este estímulo durante dos horas. Un ser humano puede reaccionar ante ciertos estímulos durante días, meses, años, o toda una vida. Se superpone así el período de impresión del salón en el de la experiencia escénica. El espectáculo visible de los períodos de intermitencia en un teatro diseñado con axialidad correcta, puede darnos una dirección que nunca recibiríamos en aquel bosque de accidentales alrededores. $\mathrm{Ni}$ siquiera en el antiguo barroco y en el teatro victoriano, preparado para proporcionar tal relajado período de dirección, durante la obertura y los entreactos, por medio de pinturas de Apolo y de las Musas sobre el telón de incendios. Alguien trató de conocer y comprender que allí, justamente en el frente, el drama se estaba desarrollando. Teatros en los cuales uno no sabe dónde han de acontecer las cosas, nunca existieron-hasta muy recientemente-. En Asia, Helas o en Basutolandia, aunque, desde luego, en Helas y en el Africa negra, el teatro fué "teatro diurno" y allí no habia pausas de oscuridad en absoluto.

No hace mucho, vi "El puente sobre el río Kwai". Llegué tarde y cogí un sitio en la segunda fila, lateral. Durante los primeros minutos me asombré ver cuán delgadas eran las piernas de los soldados, pero entré en la acción muy pronto y vi entonces la totalidad del film, bien dírigido, como si estuviese sentado en el centro del teatro, y lo recuerdo así, aparte de aquellos primeros y cortos momentos. $\mathrm{He}$ visto en Berlín Occidental "La loca de Chaillot", también en la primera fila, en una butaca obtenida gracias a la propina de mi huésped. Esta butaca se encontraba en la parte derecha del escenario, pero recuerdo realmente toda la representación como si la hubiese visto sentado en el palco imperial, en el centro de la sala.

Esta especie de necesaria y muy deseable transposición del espectador, pequena quizás o dependiente del precio que se paga, puede ser considerablemente ayudada por el arquitecto, por el diseñador de la sala, que recibe un terrible impacto de reverberación de los períodos iluminados a los oscuros en la jornada teatral.

La perseverancia objetiva de la escena, tal como la concibe el director, puede ser ayudada por el arquitecto para que dominen las perspectivas espaciales, con tendencia a mejorar los asientos más humildes. Cuando yo era todavía un muchacho, vi a Ricardo II hablando con su imagen reflejada en un espejo, en el Teatro de la Corte, en Viena. Mi memoria no me dice dónde estaba sentado, pero sí recuerdo una estampa esplendente y directa del salón, haciéndome creer que estaba en el centro de la primera fila, aunque estoy convencido de que no podía haber costeado tal entrada. Y cuando pienso en aquello, podría jurar que estaba en una butaca lateral del cuarto piso; sin embargo, nunca olvidaré que lo vi justamente frente a mí.

En Dusseldorf, unas ondas serpenteantes de impresionante luminosidad central, van desde el punto medio del entresuelo - con iluminación suave y graduada-hasta la mitad del escenario. El techo, curiosamente curvado de varias filas de palcos, está irradiado con un creciente teñido suave que embelesa la mirada, bien con una viveza reverberante, cuando las luces reostáticas se encienden, o bien con penumbra, con objeto de señalar el principio o el final del entreacto. Pero este techo visual no es un techo sólido, sino una malla completamente independiente del techo auditivo que está calculado para obtener una reverberación óptima en cualquier asiento, a un lado, en el centro, enfrente o detrás. La parte posterior del muro lateral consiste en baterias de paralelepípedos con sección triangular y con las tres caras de diferentes características de absorción y reverberación. Pulsando botones
HSCHO
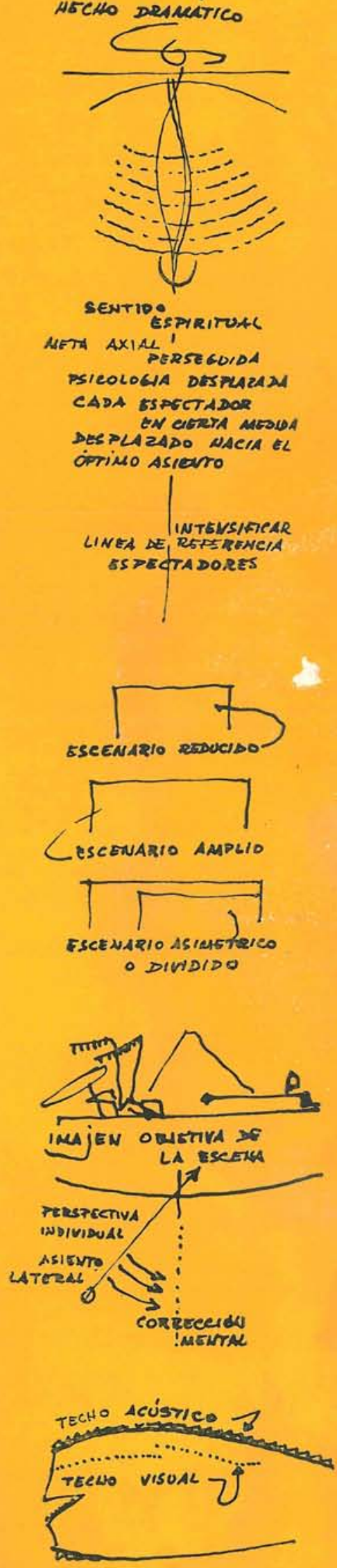


\section{planta}

Situación y esquema de trâfico.

1. "Patio de las Musas".

2. Estanque

3. Patio del pozo.

4. Entrada al escenario de per-

Sonal y visitantes.

Entrada a la sala grande.

Entrada a la sala pequeña.

. Entrada de coches.

Taquilla para servicio de

coches.

. Aparcamiento.

. Transporte de decorados.

. Montacargas.

.

.

15. Comuni montacargas. bulo.
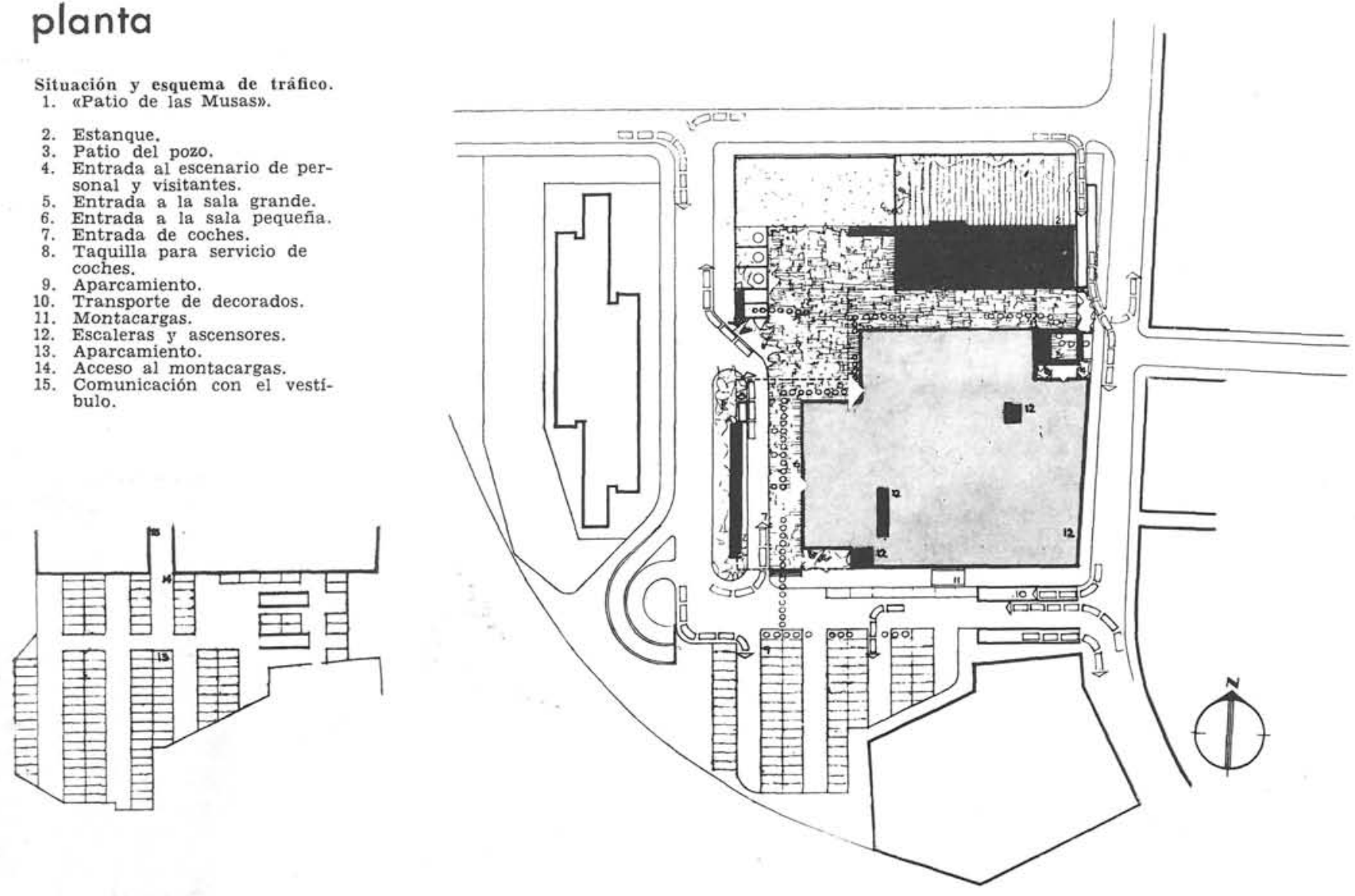

\section{teatro de Dusseldorf}

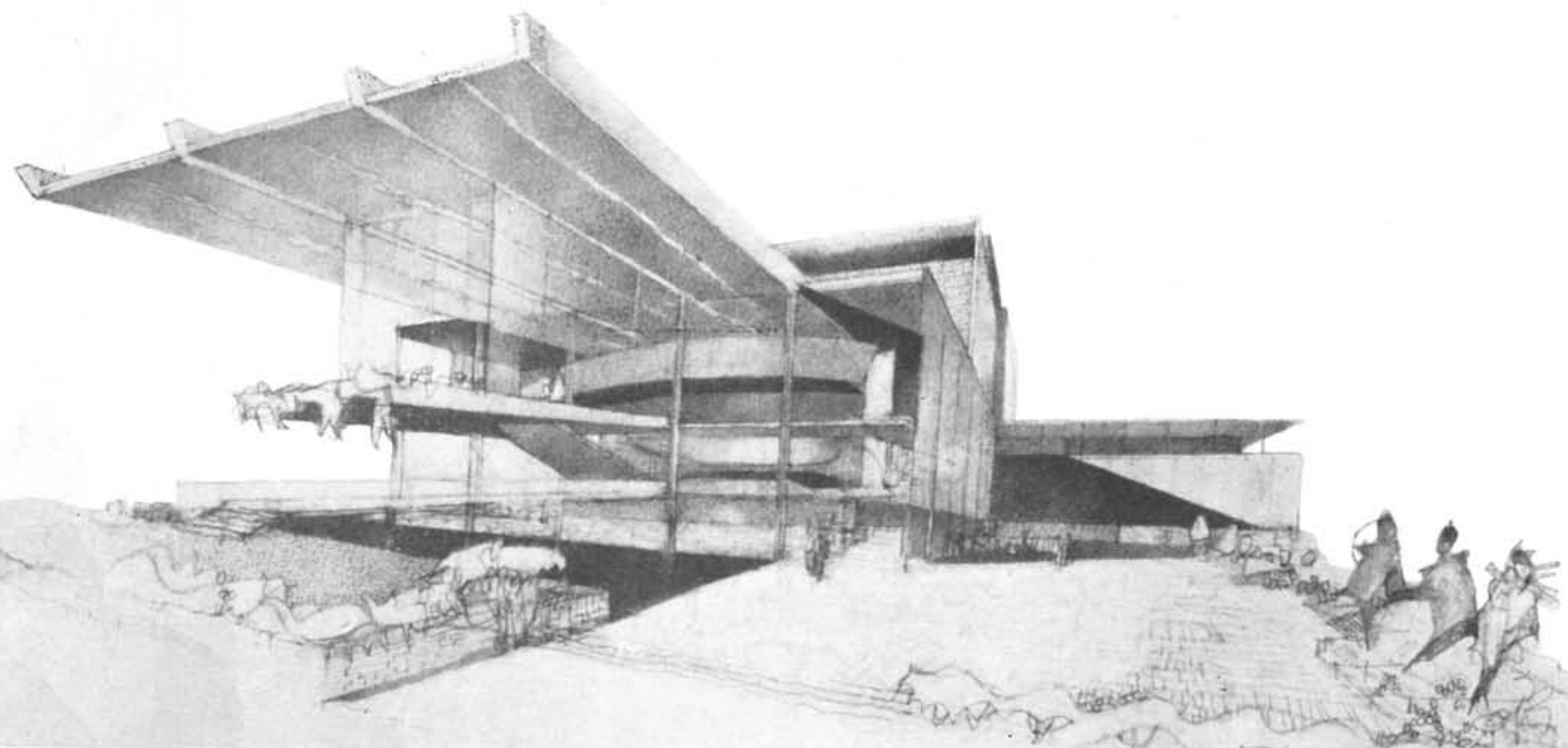




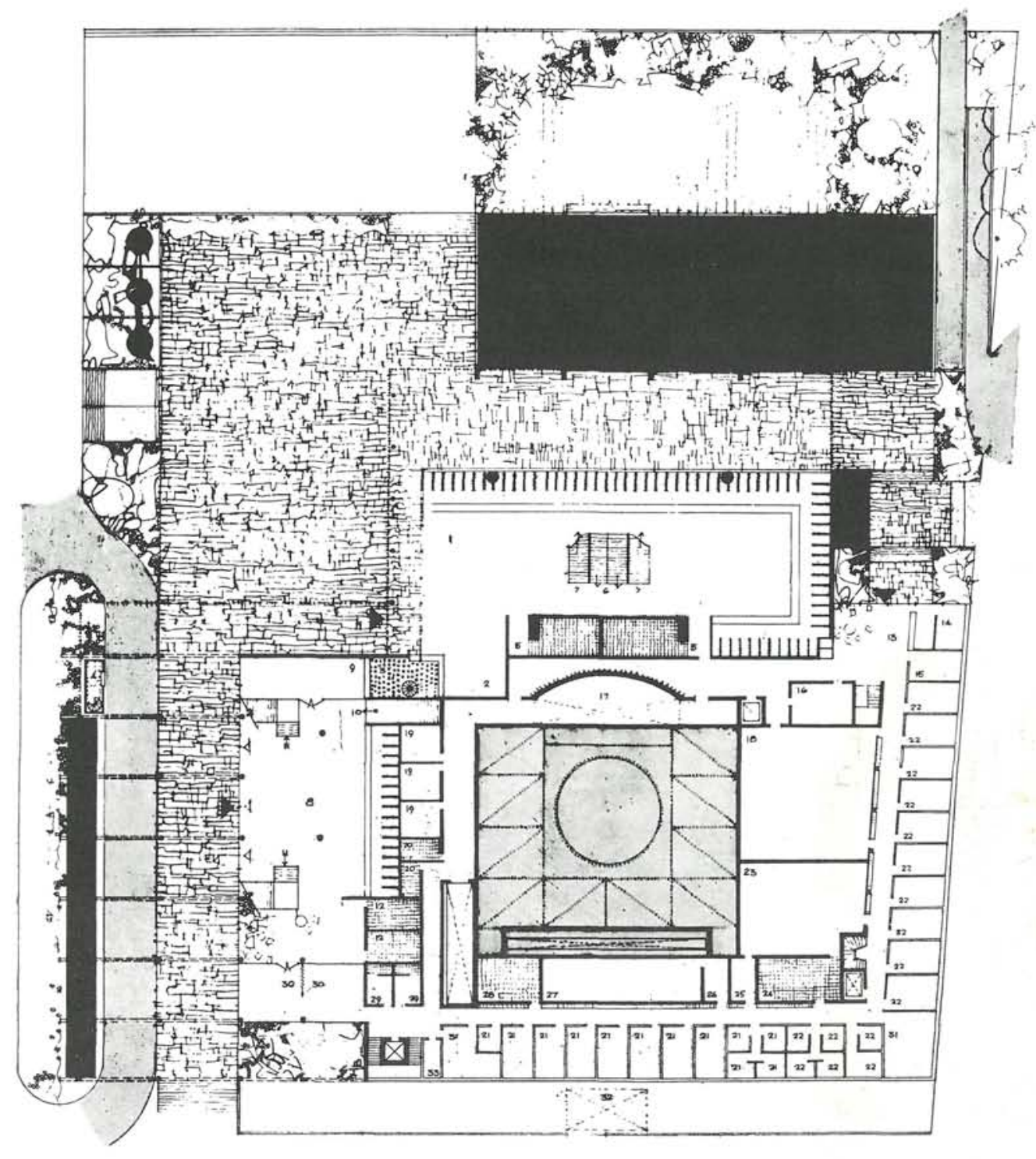

planta en cota $-1,85$

1. Entrada y vestibulo de la sala grande. -2 . Sala de taquillas, -3 . Taquillas, -4 . Taquillas para servicio de coches. -5. Lavabos.-6. Escalera al aparcamiento subterráneo,-7. Escalera hacia e vestíbulo principal.-8. Entrada y vestíbulo de la sala pequeña.-9. Sala de taquillas.-10. Escalera al aparcamiento subterráneo.-11. Escalera al vestibulo principal.-12. Lavabos.-13. Entrada escenario.-14. Portería.-15. Central de teléfonos.-16. Sereno.-17. Foso de la orquesta.-18. Escenario de ensayos.-19. Administración. - 20. Lavabos. -21. Vestuarios independientes para señoras. -22 . Vestuarios independientes para señores. -23. Vestuario general para caballeros.-24. Duchas lavabos para caballeros.-25. Maquillaje para caballeros. -26. Maquillaje para senoras. - 27. Veslicos sobre el escenario.-33. Trastero.
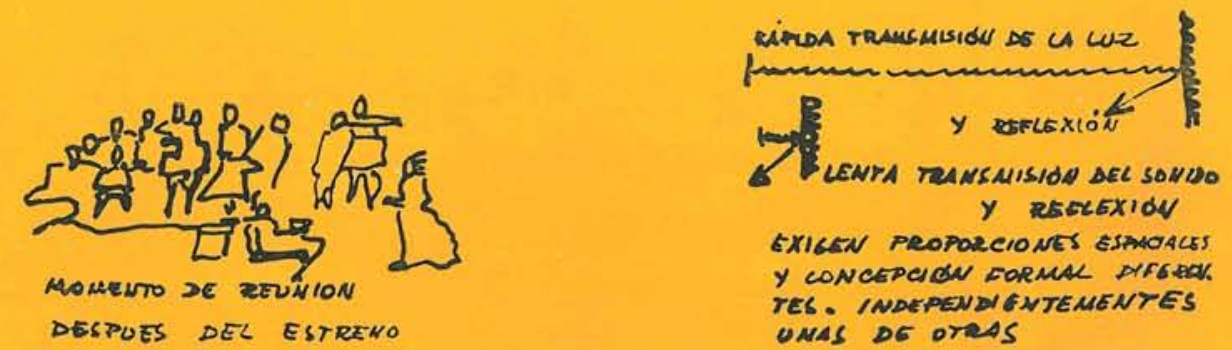
planta en cota $+1,90$

1. Vestíbulo--2. Bar.-3. Escalera del guardarropas y del vestibulo.-04. Escalera al vestíbulo superior. - 5. Foso de la orquestaanteescenario. -6 . Nichos de iluminacion.-7. Organo.-8. Escenario principal.-9. Escenario lateral.-10. Escenario trasero.-11. Lavabos.-12. Servicio contra incendios. -13 . Servicio de sanidad. 14. « Sala verden-sala de estar. 4. Antesala, 18. Dibujantes. Asistente. 18, Dibujantes. 19. Cama oscura. Director des. cen 23 Director de iluminción - 24. Vestuario para personal y artistas - 25 . Almacén. nal alm de decorados.Álmacén de prospectos y monta cargas escenario - -28 . Estancia para imágenes plásticas -29. Al macén de gran altura para ma terial practicable, -30 . Almacén de muebles.

\section{planta}

en cota $+5,65+5,30$

1. Sala grande de espectáculos 2. Vestíbulo.-3. Sala pequeña de espectaculos. -4 . Sala de fumar madares-7. Escaler Sala de fuza - Escalera al a terraferior - Parte alte del in cén - 10. Almacén-11. Lavabos. 2. Sala de descanso-13. Antesala -14. Dirección-15. Sastrería de señoras - 16. Sastrería para caballeros - 17 . Probador18. Modista -19. Sastrería señoras. -20 , Sastrería caballeros 21. Pintura, teñido, lavado - 22 . Desinfección,-23. Maquillaje.
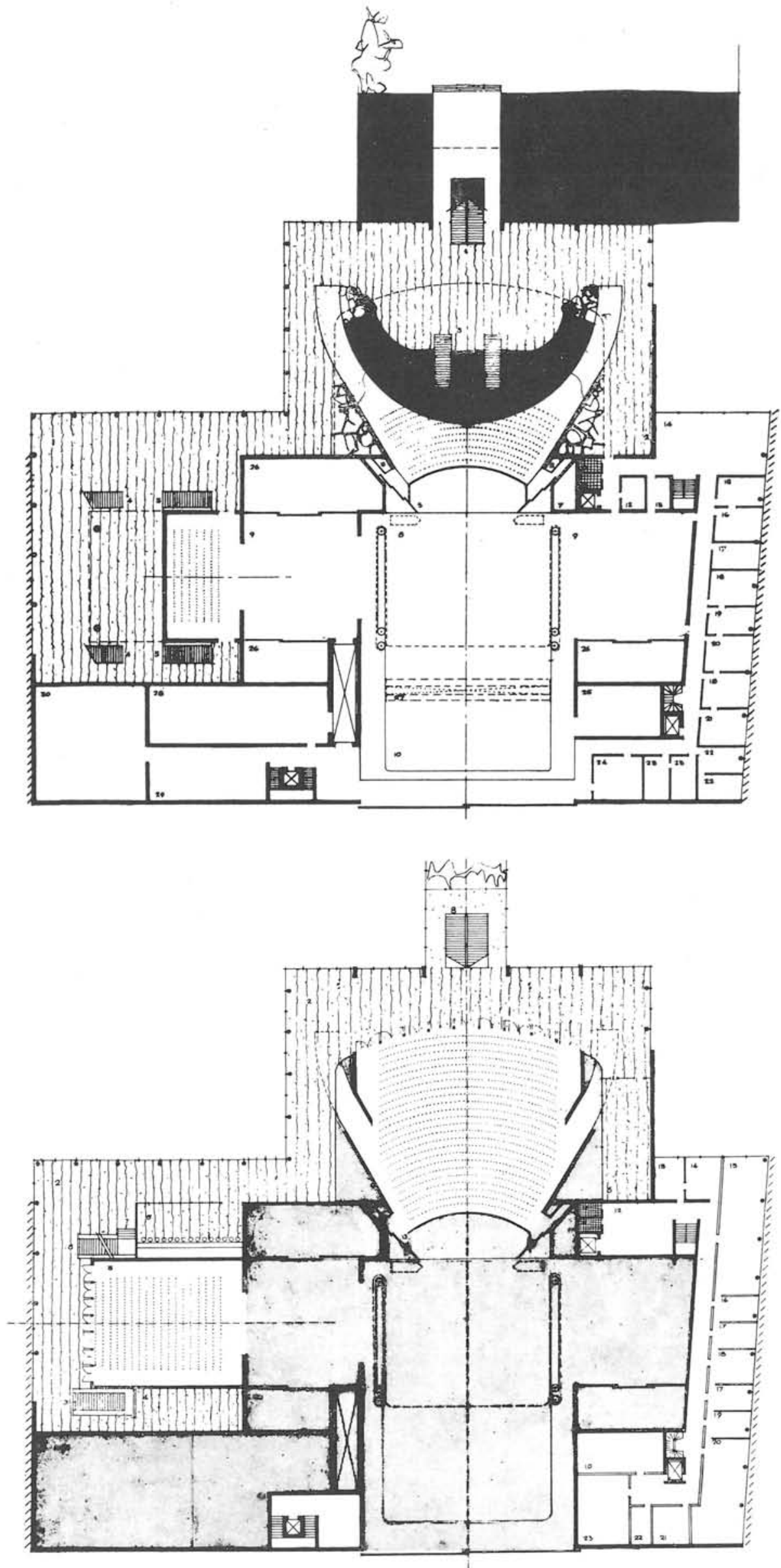


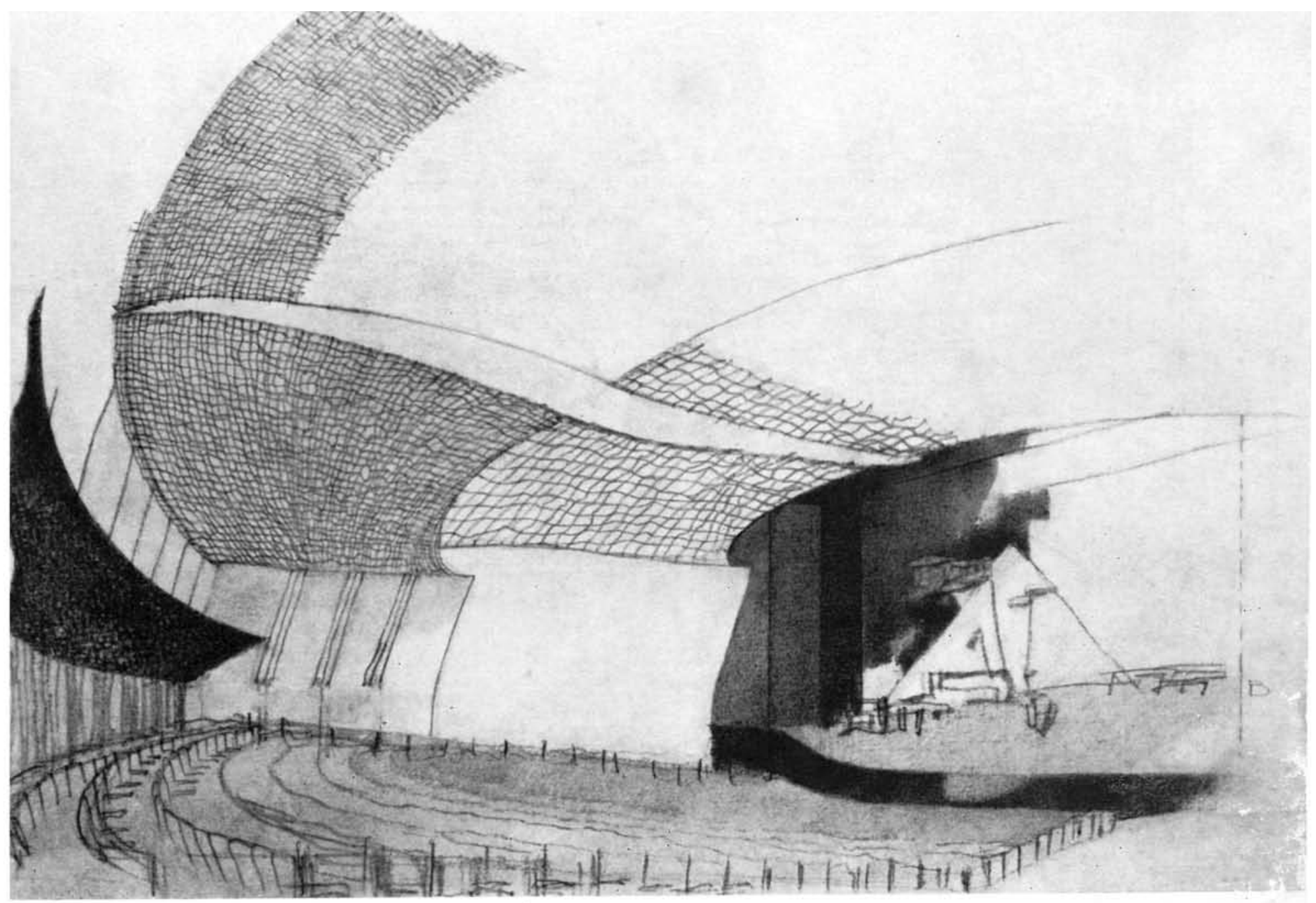

interiores

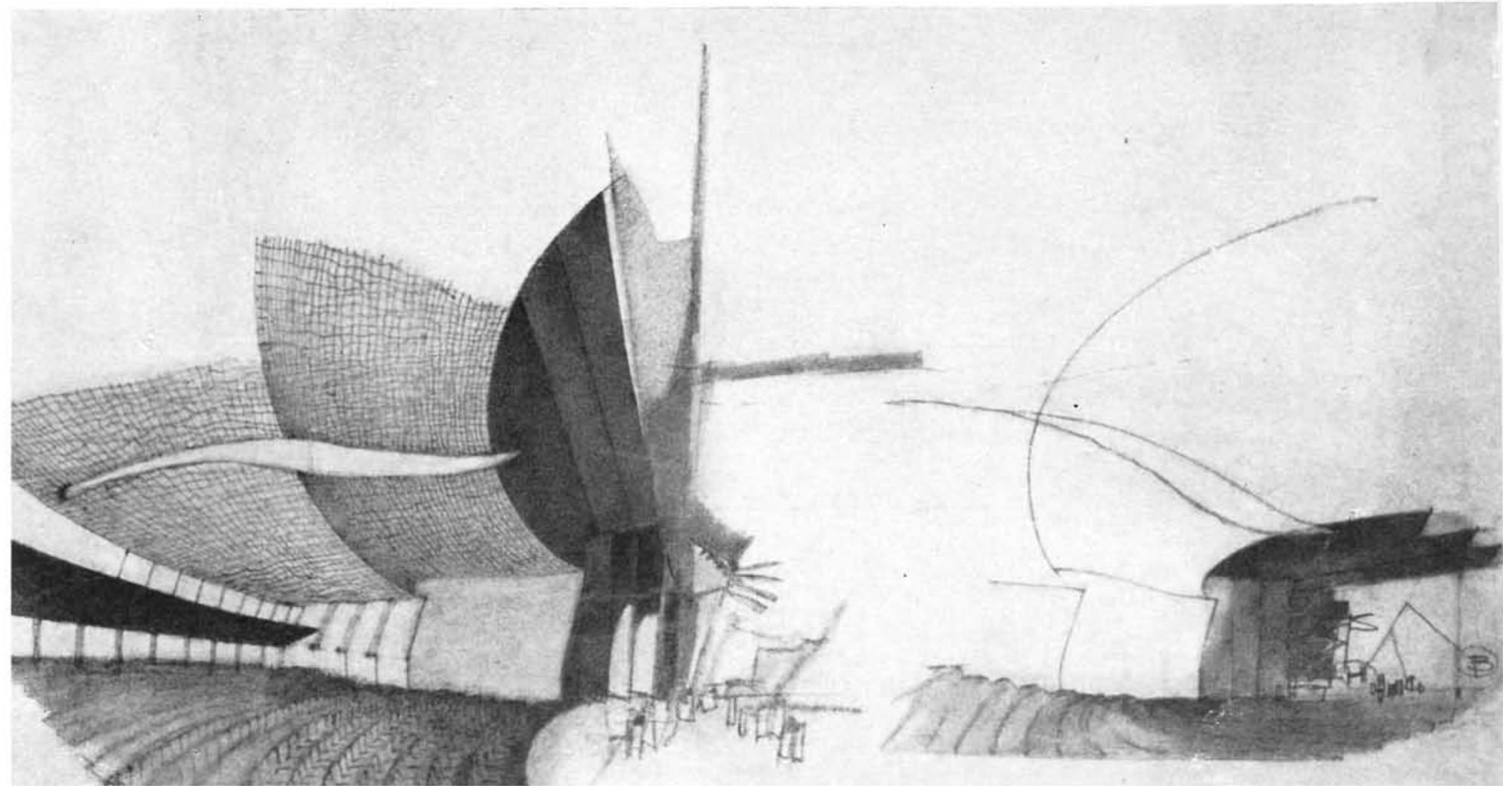


especiales puede cambiarse la iluminación, a voluntad, durante la representación y ser regulada la entonación auditiva; la iluminación y la acústica pueden también ser incrementadas cuando la escena de la batalla alcanza su punto álgido, o cuando el espíritu pronuncia sus últimas e inolvidables palabras. No hay razón alguna para hacer estática acústicamente una sala, durante un drama, mientras que es dinámica la iluminación visual solamente.

Muchas características del teatro americano han sido adaptadas en Dusseldorf, a donde Richard J. Neutra fué invitado-junto con otros dos arquitectos extranjeros, Le Corbusier, de París, y Mies Van der Rohe, el gran alemán que trabaja actualmente en Chicago-para exponer este proyecto. Por ejemplo, Neutra cree que un salón verde, para conversar, con adornos perfumados, gustaría también a los espectadores alemanes, que se pondrían el "smoking" y dejarían sus trajes y faldas corrientes, para asistir a tan grande y social ocasión como es una representación.

Los alemanes honran a sus famosos directores con una gran deferencia; ellos aplauden a sus mejores actores, y hacen que se levante el telón repetidas veces. Pero también han invertido, y siguen invirtiendo, interés y dinero en teatros, como si fueran templos, pues ellos los consideran como tales. Un teatro es templo donde cultivar el espiritu, mientras que un templo es venerable; pero sólo tiene un significado más profundo, para la naturaleza humana, proyectado en su futuro.

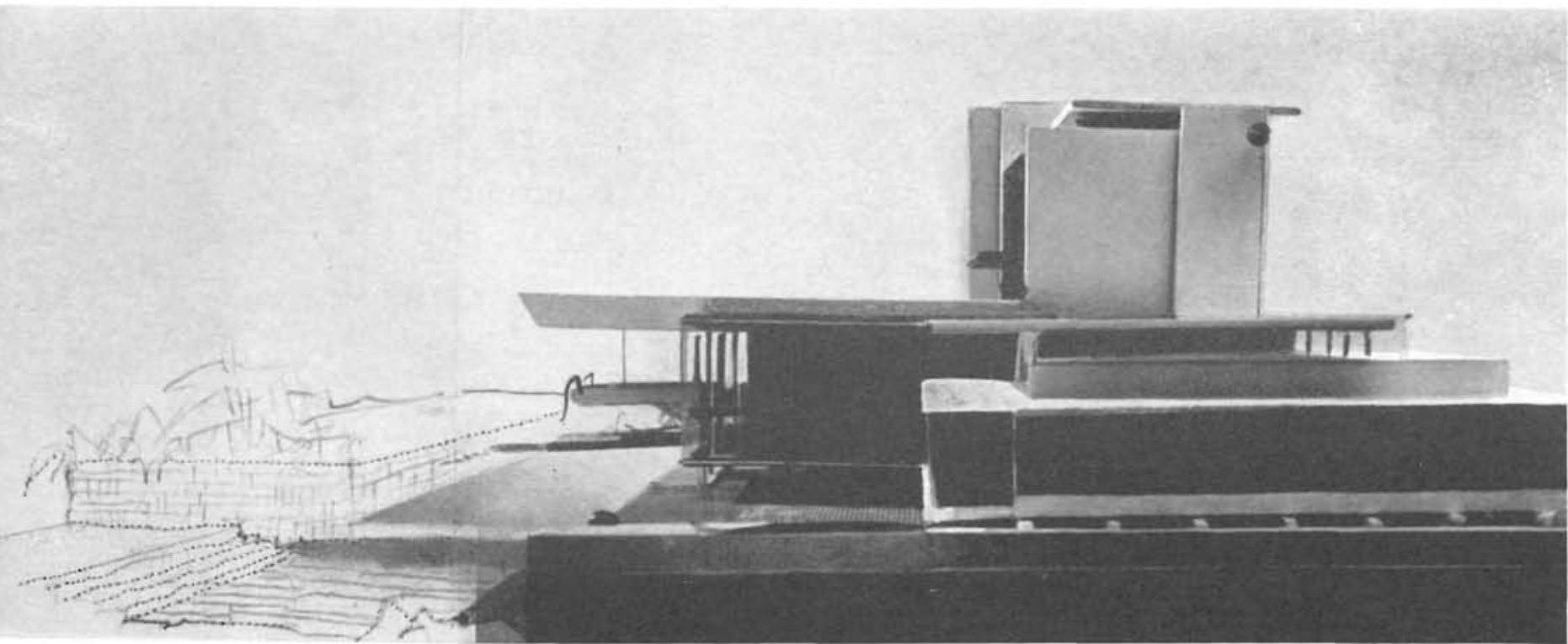

